\title{
Morphological and anatomical aberrations induced by waterlogging in sugarcane
}

\begin{tabular}{lll}
\hline Paper received: 19.04 .2018 & Revised received: 16.09 .2018 & Re-revised received: 04.10 .2018 \\
\hline
\end{tabular}

\section{Authors Info \\ R. Jain*, A. Singh, S.P. Singh, A. Chandra and A.D. Pathak \\ Plant Physiology and Biochemistry Division ICAR-Indian Institute of Sugarcane Research, Lucknow-226 002, India}

*Corresponding Author Email : radha_dinesh@yahoo.co.in

\section{Edited by \\ Dr. Nandjee Kumar}

\section{Reviewed by \\ Dr. Jagdish Daggar \\ Dr. R.B. Raizada}

\section{Abstract}

Aim : The present investigation was carried out to study root anatomy of sugarcane cultivars (CoLk 94184 and CoJ64) planted under waterlogged condition through Scanning Electron Microscopy (SEM).

Methodology : Two sugarcane (Saccharum spp. hybrid) cultivars, CoLk 94184 and CoJ 64 were evaluated for changes in root anatomy in response to waterlogging during 2017-2018. For waterlogging treatment, crop was grown in deep plot which was waterlogged upto a depth of $1 \mathrm{~m}$ during active grand growth stage (monsoon season) along with untreated control plot. After three months of waterlogging, the plants were uprooted to study the root morphology and anatomy through SEM.

Results : Waterlogged plants showed aerial root formation in both the cultivars but number and mass were higher in CoJ64. Aerenchyma was formed in the cortical region of both control and waterlogging roots but the size was relatively increased in waterlogged. Control Roots Irregular and damaged surface cells with longer root hairs were observed in waterlogging treatment. Waterlogged roots exhibited cell distortion, loss of uniformity in endodermis and pericycle regions and higher number of metaxylem vessels.

Interpretation : The study concluded that waterlogging treatment caused structural

Root anatomy of sugarcane cultivars in response to waterlogging through SEM

anomalies and induced anatomical and surface ultra-structural changes in both the cultivars, but the level of deformation was relatively higher in genotype CoJ 64, indicating sensitivity towards waterlogging as compared to cultivar CoLk 94184.

Key words: Abiotic stress, Anatomical aberrations, Rootanatomy, Sugarcane, Waterlogging

How to cite : Jain, R., A. Singh, S.P. Singh, A. Chandra and A.D. Pathak :Morphological and anatomical aberrations induced by waterlogging in sugarcane. J. Environ. Biol., 40, 634-640 (2019). 


\section{Introduction}

Sugarcane is an important sugar crop that encounter both biotic and abiotic stresses during its active growth phases (Islam et al., 2011). Waterlogging is one of the serious abiotic stresses which causes tiller mortality, aerial rooting, crop lodging, reduced relative growth rate and cane yield. In India, waterlogging is associated with monsoon rainfall and improper drainage system. Reduction in cane yield and juice quality attributes due to waterlogging depends upon genotypes, environmental conditions, developmental stages, submergence level and duration. Waterlogging tolerance is linked with physiological and anatomical adaptations of plants (Ashraf, 2012; Gomathi et al., 2015); the tolerant species form aerenchyma under anoxic conditions (Drew, 1997). Flooding depth, duration and flow of water in the field are some of the factors adversely affecting crop growth; however, flooding effect on sugarcane physiology and productivity remains inconclusive (Jain et al., 2017a).

Genetic variability was observed among sugarcane genotypes as per cane yield and juice quality attributes are concerned (Jain et al., 2017a, b). Some of the genotypes grown under hypoxia condition showed higher or unaffected cane yield (Glaz et al., 2002; 2004a). Glaz et al. (2004b) also observed neutral or positive response of gas exchange characteristics of sugarcane to flooding. Two cultivars of sugarcane when grown between water table depths of 32-84 cm did not show any yield difference (Gascho and Shih, 1979). Several workers also reported marked reduction in growth under anoxia conditions (Hasan et al., 2003; Rahman et al., 1989; Webster and Eavis, 1972). Higher water table during elongation phase adversely affects stalk weight and shoot population, resulting in yield loss @ $1 \mathrm{t} \mathrm{ha} \mathrm{A}^{-1}$ for one $\mathrm{cm}$ increase in water level (Carter and Floyed, 1974). A shift in respiratory mechanism from aerobic to anaerobic process is one of the main effects of oxygen deficiency due to waterlogging. Several morphological, anatomical and physiological alterations take place in plants for the sake of adaptation or survival under waterlogging stress. In view of the above, the present investigation was carried out to study the root anatomy of sugarcane cultivars (CoLk 94184 and CoJ64) planted under waterlogged condition through Scanning Electron Microscopy.

\section{Materials and Methods}

Experimental design: Two sugarcane (Saccharum spp. hybrid) cultivars, CoLk 94184 and CoJ 64, were evaluated for changes in root anatomy in response to waterlogging during 2017-2018. For waterlogging treatment, the crop was grown in deep plot at Kharika Block, ICAR- Indian Institute of Sugarcane Research, Lucknow, India which was waterlogged upto one meter depth during grand growth stage (monsoon season) along with untreated control plot. After three months of waterlogging, the plants were uprooted to study the root morphology and anatomy. Data on stalk elongation rate of waterlogged affected plants, dry weight of shoot (sum of leaf, stalk and leaf sheath weight) and root tissues (sum of both shoot root (SR) and aerial root (AR)) were measured. SR/AR ratio was calculated using shoot root and aerial root weight of waterlogged affected plants. The stalk elongation rate was calculated as follows:

Stalk elongation rate $(\mathrm{cm} /$ day) $=$ stalk height $(\mathrm{cm})$ before waterlogging (T1) - stalk height (cm) after waterlogging (T2)/ no of days

Scanning Electron Microscopy: Shoot-roots and aerial roots of sugarcane cultivars (CoLk 94184 and CoJ 64) were excised, washed with tap water several times to remove soil particles accumulated on their surface, rinsed with distilled water and stored at $4^{\circ} \mathrm{C}$ for anatomical and surface ultra structural investigations through SEM. The apical portion of the roots attached to stalk $(\sim 2.0 \mathrm{~cm})$ was first washed with distilled water to remove contamination and then washed samples were fixed in glutaraldehyde $\left(2.5 \%\right.$, v/v, in $200 \mathrm{mM} \mathrm{PO}_{4}^{3-}$ buffer; $\left.\mathrm{pH} 7.0\right)$ and stored at $4^{\circ} \mathrm{C}$ in a refrigerator. Before processing the samples for SEM, the samples were shifted twice in fresh fixative within $1 \mathrm{hr}$. The fixed roots were rinsed five times with sucrose $(7 \%, v / v$, in $100 \mathrm{mM} \mathrm{PO}_{4}^{3-}$ buffer; $\mathrm{pH} \mathrm{7.0)}$ solution to remove the traces of glutaraldehyde. The fixed samples were dehydrated through a series of dehydrating solution $(30,50,70$, and $80 \%$ alcohol for 15 min each; $90 \%$ alcohol for $20 \mathrm{~min} ; 100 \%$ alcohol for $30 \mathrm{~min}$; alcohol/amyl acetate, 1:1, v/v and amyl acetate for $15 \mathrm{~min}$ each) and subjected to critical point drying. The dehydrated roots were mounted on stubs with the help of double stick tape and sputtered with a film of gold using an ion-beam sputter coater. The samples were examined under FEI Quanta 250 Scanning Electron Microscope at CSIR-Central Drug Research Institute; Lucknow (India).The secondary images were acquired at different magnifications $(\times 50, \times 170, \times 250$ and $\times 500)$ with an image analyzer attached to the microscope.

\section{Results and Discussion}

The results of the present investigation showed that root dry mass were relatively higher in both the cultivars (0.0257 $0.0295 \mathrm{~kg}$ ) under waterlogged condition than control plants $(0.0098-0.0195 \mathrm{~kg})$. Increase in root dry mass might be due to aerial root formation at each node submerged under waterlogged conditions, a peculiar feature of sugarcane crop having a viable bud and root primordia at nodal region or due to higher root density (Avivi et al., 2016). Aerial roots help in maintaining root activity by supplying necessary oxygen (Drew, 1997; Hidaka and Karim, 2007), however, the shoot dry weight $(0.859 \mathrm{~kg})$; elongation rate $(0.664 \mathrm{~cm} /$ day) and SR/AR ratio (3.053) were comparatively higher in CoLk 94184 as compared to cultivar CoJ $64(0.727 \mathrm{~kg}, 0.124 \mathrm{~cm} /$ day and 2.161 , the shoot dry weight, elongation rate and SR/RA ratio, respectively) under waterlogged condition. Increase in root and shoot weight, stalk elongation rate and SR/AR ratio in genotype CoLk 94184 indicated tolerance to waterlogging stress. Increase in these attributes might be due to higher K, P, chlorophyll content contents, SPAD under waterlogged conditions in cultivar CoLk 94184 (Jain et al., 2017a). Similarly, the number of metaxylem vessels varied 
among control (9-10), waterlogged (13-14) and aerial roots (811); the waterlogged roots showed highest number of metaxylem vessels. Metaxylem vessels help in transport of water and nutrients to the growth tissues.

The SEM studies revealed that waterlogging treatment causes morpho-anatomical changes and structural anomalies in roots of sugarcane cultivars, CoLk 94184 and Co J64 when compared with untreated control. The outer layer of root was intact with more or less uniform surface cells in control plants (Fig. $1 \mathrm{a}, \mathrm{d}$; 2a, d); however, in waterlogged roots, the surface cells appeared irregular and damaged suggesting waterlogging induced alterations in both the cultivars (Fig. 1b, e; 2b, e); the effects were found severe in cultivar CoJ 64. These alterations may be due to decrease in pectin content and degradation of cell wall polysaccharides as observed in maize seedlings exposed to waterlogging (Vitorino et al., 2001; Gall et al., 2015). A magnified view of the surface cells revealed different level of surface injury even scrapped off in waterlogging treated roots as compared to the control (Fig. 2b, e). In control plants, the surface cells were apparently intact with no injury (Fig $2 a, d$ ), whereas in waterlogging treated roots, these cells were totally damaged (Fig. $2 b, e)$ and scrapped off (Fig. 2b; 3b, e), the injury level was different and deep grooves with wide cavities were apparent at
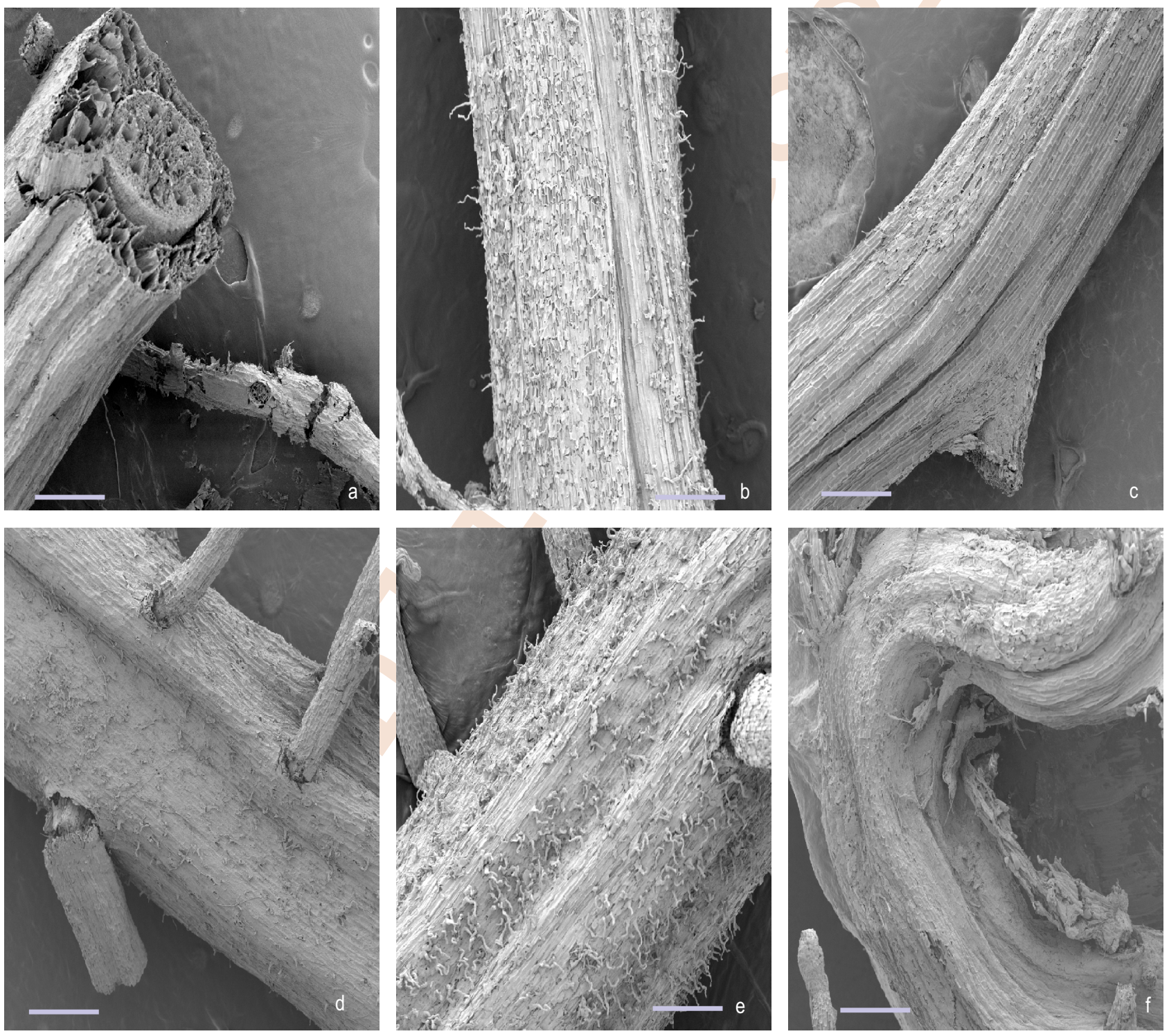

Fig. 1: Scanning electron micrographs $(\times 50)$ of root surface of sugarcane showing the effect of waterlogging treatment: (a) CoLk 94184 (control root); (b) CoLk 94184 (waterlogged root); (c) CoLk 94184 (aerial root); (d) CoJ 64 (control root); (e) CoJ 64 (waterlogged root) and (f) CoJ 64 (aerial root); Bar $1000 \mu \mathrm{m}$. 



Fig. 2: Scanning electron micrographs ( $\times 250)$ of root surface of sugarcane showing the effect of waterlogging treatment: (a) CoLk 94184 (control root); (b) CoLk 94184 (waterlogged root); (c) CoLk 94184 (aerial root); (d) CoJ 64 (control root); (e) CoJ 64 (waterlogged root) and (f) CoJ 64 (aerial root); Bar 200um. SC-scrapped off cell; DC-damaged cells; DRH-dense root hairs.

many places (Fig. 2b, e). The surface cells were totally damaged, irregular patches of cells were noticed at regular intervals and cells were ruptured (Fig. $2 b, e ; 3 b, e)$. The distortion as well as withering and irregularities in the root surface cells might be due to the direct effect of waterlogging on cell wall (Ponnamperuma, 1972). Das et al. (2015) also reported lesser membrane integrity and higher structural damage in sensitive cultivar of tea plant exposed to drought condition. Aerial roots formed in waterlogged plants showed low level of injury (Fig. 1-4 c, f). Ooume et al. (2009) reported that waterlogging treatment caused thinning of cell wall in Azuki bean seedling, and was directly correlated to cell wall sugar content. The distorted root structures inhibit entry of both nutrients and water into the plant (Askari et al., 2007).

Root surface of waterlogged roots revealed withered cells and manifold increase in root hairs, and these were apparently longer and dense (Fig. 2b, 2e). In the present study, enhanced root hair development was noted in both the cultivars, but their numbers were higher in CoJ 64 cultivar. Exposure to waterlogging indirectly induces oxidative stress, resulting in inhibition of root growth and accumulation of reactive oxygen species (Kaur et al., 
2012). Root hair growth is positively linked to the accumulation of superoxide anions in root hair tips indicating lower tolerance to waterlogging (Foreman et al., 2003). Root hairs are responsible for conducting water and nutrients from soil to plant roots.

These root hairs ultimately affect the conduction of water into the xylem tissues, while nutrients enter directly from water into the root. In the present study, irregular arrangement of exodermis and outer cortical cells is similar to the observations in waterlogged affected maize roots by De Souza et al. (2009). The damaged cortical cells may be responsible for disrupted diffusion of nutrients into the central cylinder of the root. Shoot-roots of both control (well drained) and waterlogged affected plants showed aerenchyma formation in cortex region (Fig. 4) but size of aerenchyma was relatively higher in waterlogged plants (Fig. 4b, e). This additional aerenchyma apparently formed due to cell lysis. Similarly, aerial roots formed under waterlogged condition showed formation of aerenchyma in the cortical region of both the cultivars (CoLk 94184 and CoJ64), however, it was lesser in cultivar CoJ 64 (Fig. 4c, f). Formation of aerenchyma is essential for the survival and functioning of plants subjected to waterlogging. The aerenchyma contributes $\mathrm{O}_{2}$ supply from shoots to roots and for the ventilation of gases (e.g. $\mathrm{CO}_{2}$ and methane) (Colmer, 2003; Cardoso et al., 2013; Ashraf, 2012). Aerenchyma
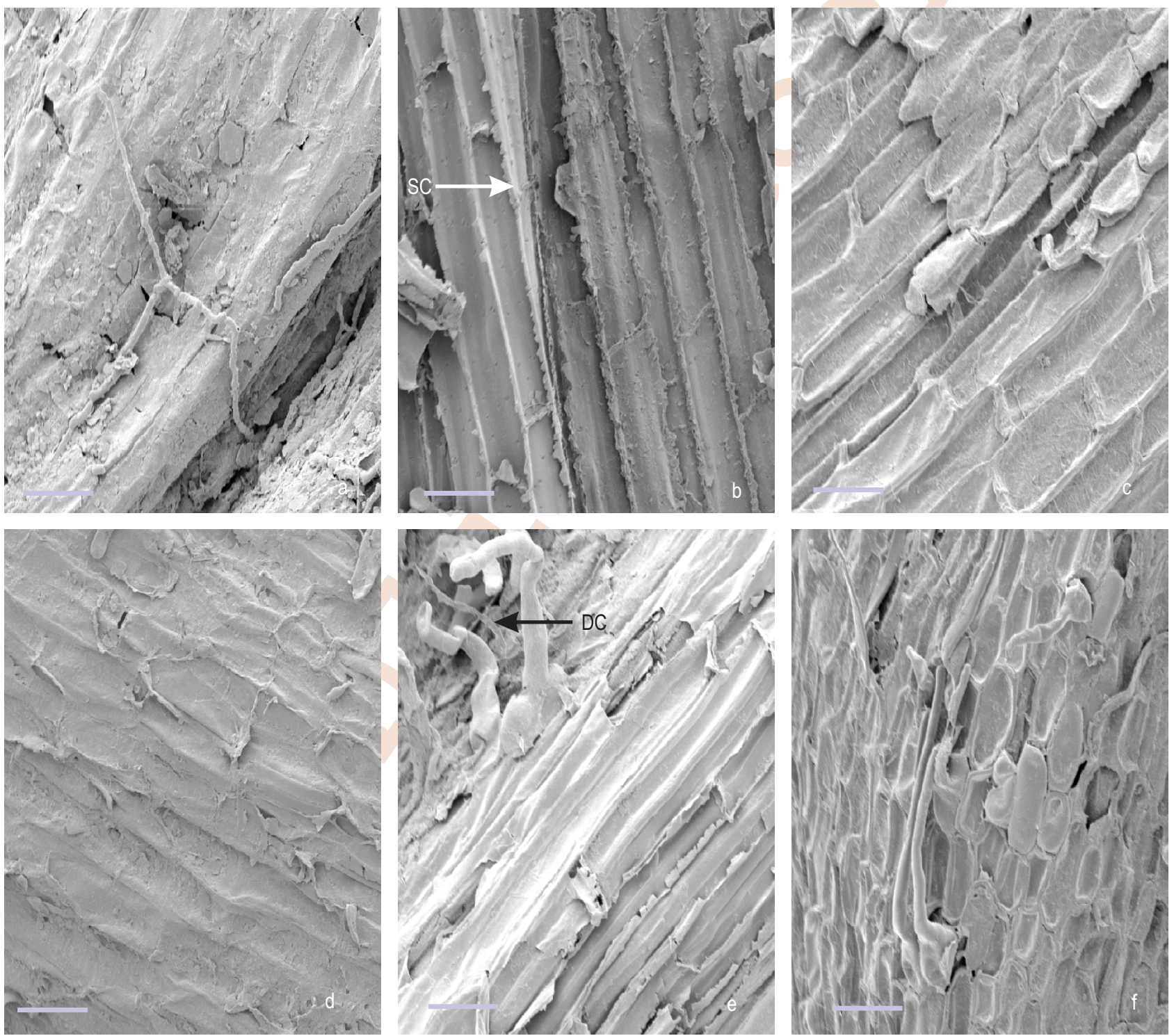

Fig. 3: Scanning electron micrographs ( $\times 500)$ of root surface of sugarcane showing the effect of waterlogging treatment: (a) CoLk 94184 (control root); (b) CoLk 94184 (waterlogged root); (c) CoLk 94184 (aerial root); (d) CoJ 64 (control root); (e) CoJ 64 (waterlogged root) and (f) CoJ 64 (aerial root); Bar $100 \mu \mathrm{m}$. SC-scrapped off cell; DC- damaged cells. 

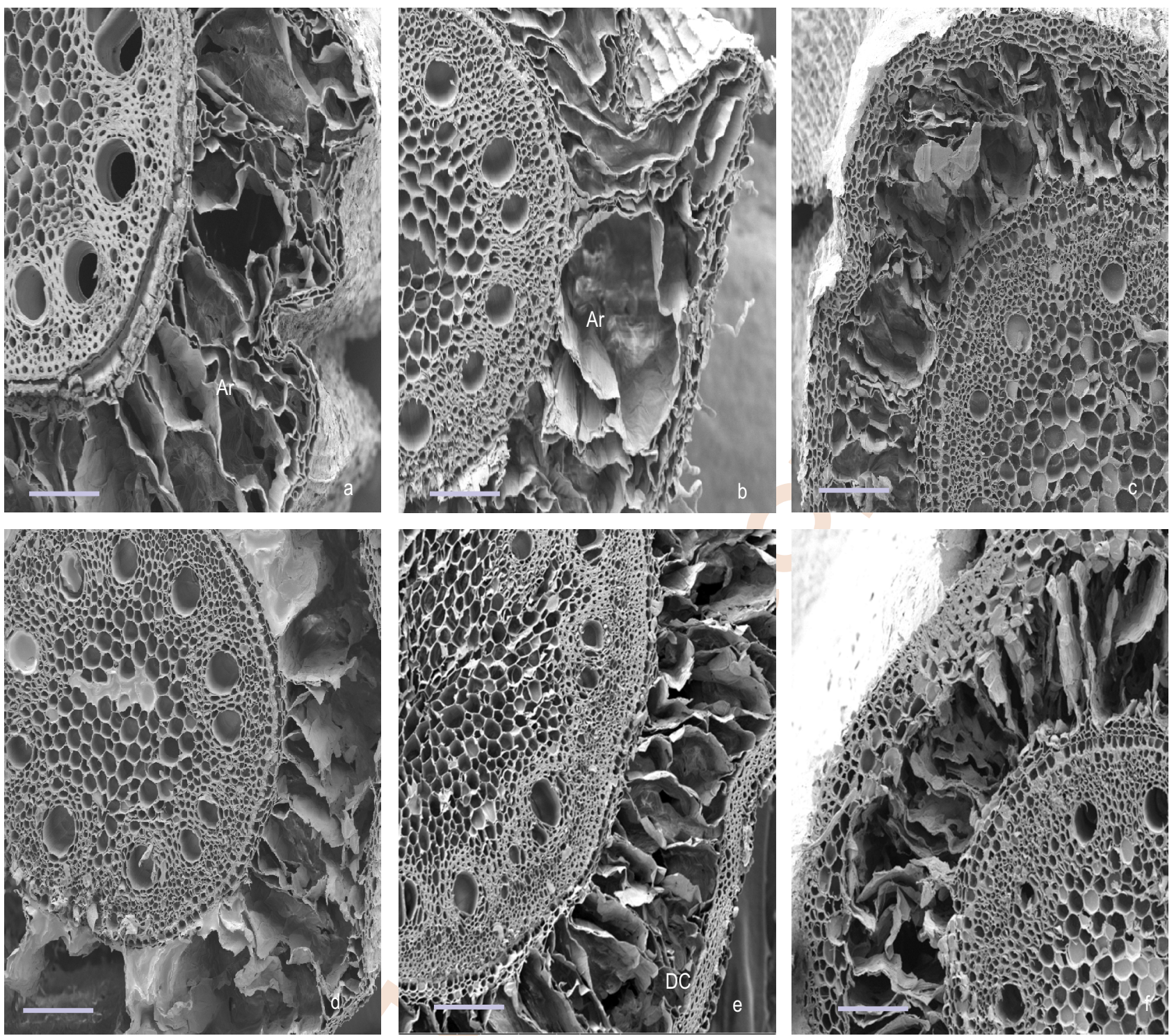

Fig. 4: Scanning electron micrographs ( $\times 170)$ of cross section of root of sugarcane showing the effect of waterlogging treatment: (a) CoLk 94184 (control root); (b) CoLk 94184 (waterlogged root); (c) CoLk 94184 (aerial root); (d) CoJ 64 (control); (e) CoJ 64 (waterlogged root) and (f) CoJ 64 (aerial root); Bar -

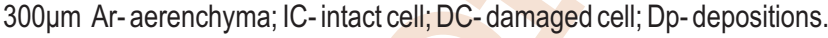

may provide photosynthetic benefit by concentrating $\mathrm{CO}_{2}$ from root respiration and transporting it to intercellular spaces in leaves (Constable and Longstreth, 1994). In the present study, aerenchyma formed in the cortex of roots are similar to rice under well drained soil conditions and its formation can be further enhanced during soil waterlogging (Yamauchi et al., 2018). The former and latter are defined as constitutive and inducible aerenchyma formation (Colmer and Voesenek, 2009). Constitutive aerenchyma formation under non-waterlogged conditions might be beneficial for tissue survival immediately after the onset of low-oxygen conditions (Yamauchi et al., 2016). The present study revealed that two sugarcane cultivars varied in tolerance to waterlogging experienced drastic changes in root morphology and anatomy when subjected to three months waterlogged condition. The cultivar CoJ64 is comparatively more sensitive to waterlogging than CoLk 94184 so far as root structure and anatomical aberrations are concerned.

\section{Acknowledgments}

The authors gratefully acknowledge the Director, ICARIndian Institute of Sugarcane Research, Lucknow to carry out the research work and to the Director, CSIR-Central Drug Research Institute, Lucknow for providing SEM facility. 


\section{References}

Ashraf, M.A.: Waterlogging stress in plants: A review. African J. Agricult. Res., 7, 976-1981 (2012).

Askari, S., F. Uddin and R. Azmat: Biosorption of Hg: I. Significant improvement with marine green algae in the anatomy of hypocotyl of Trigonellafoenum-graecum under $\mathrm{Hg}$ stress. Pak. J. Bot., 39, 1089- 1096 (2007).

Avivi, S., S.S. Slameto and R.A. Ramadhan: Physiological characters of sugarcane after flooding stress. Agric. Agricult. Sci. Procedia, 9, 31-39 (2016)

Cardoso, J.A., J. Rincón, J.D.L.C. Jiménez, D.N. Diana and I.M. Rao: Morpho-anatomical adaptations to waterlogging by germplasm accessions in a tropical forage grass. AoB Plants, 5, 1-14 (2013).

Carter, C.E., and J.M. Floyed: Inhibition of sugarcane yields by high water level during dormant season. Proc. Amer. Soc. Sugar Cane Technol., 4, 14-18 (1974).

Colmer, T.D. and L.A.C.J.Voesenek: Flooding tolerance: Suites of plant traits in variable environments. Funct. Plant Biol., 36, 665-681 (2009).

Colmer, T.D.: Long-distance transport of gases in plants: A perspective on internal aeration and radial oxygen loss from roots. Plant Cell Environ., 26, 17-36 (2003).

Constable, J.V.H. and D.J. Longstreth: Aerenchyma carbon dioxide can be assimilated in Typha latifolia L. leaves. Plant Physiol., 106, 1065-1072 (1994).

Das, A., M. Mukhopadhyay, B. Sarkar, D. Saha and T.K. Mondal: Influence of drought on cellular ultrastructure and antioxidant system in tea cultivars with different drought sentivities. J. Environ. Biol., 36, 875-882 (2015).

De Souza, T.C., E.M. De Castro, F.J. Pereira, S.N. Parentoni and P.C. Magalhăes: Morpho-anatomical characterization of root in recurrent selection cycles for flood tolerance of maize (Zea mays L.). Plant Soil Environ., 55, 504-510 (2009).

Drew, M.C.: Oxygen deficiency and root metabolism: Injury and acclimation under hypoxia and anoxia. Ann. Rev. Plant Physio. Plant Mol. Biol., 48, 223-250 (1997).

Foreman, J., V. Demidchik, J.H.F. Bothwell, P. Mylona, H. Miedema, M.A Torres, P. Instead, S. Costa, C. Brownlee and J.D.G. Jones: Reactive oxygen species produced by NADPH oxidase regulate plant cell growth. Nature, 422, 442-446 (2003).

Gall, H.L., F. Philippe, J.M. Domon, F. Gillet, J. Pelloux and C. Rayon: Cell wall metabolism in response to abiotic stress. Plants, 4, 112166 (2015).

Gascho, G.J. and S.F. Shih: Varietal response of sugarcane to water table depth: 1. Lysimeter performance and plant response. Soil Crop Sci. Soc. Fla. Proc., 38, 23-27 (1979).

Glaz, B., D.R. Morris and S.H. Daroub: Sugarcane photosynthesis, transpiration and stomatal conductance due to flooding and water table. Crop Sci., 44, 1633-1641 (2004a).

Glaz, B., D.R. Morris and S.H. Daroub: Periodic flooding and water table effects on two sugarcane genotypes. Agron. J., 96, 832-838 (2004b).

Glaz, B., S.J. Edme, J.M. Miller, S.B. Milligan and D.G. Holder: Sugarcane cultivar response to high summer water tables in the Everglades. Agron. J., 94, 624-629 (2002).

Gomathi, R., P.N. Gururaj, K. Chandran and A. Selvi: Adaptive responses of sugarcane to waterlogging stress: An overview. Sugar Tech, 17, 325-338 (2015).

Hasan, M.F., M.R. Alam, M.A. Jabber, M.K. Begam and M.A.S. Miah: Effects of waterlogging on juice quality and yield of sugarcane. Pak. J. Biol. Sci., 6, 1151-1155 (2003)

Hidaka, T. and M.A. Karim: Flooding tolerance of sugarcane in relation to growth and root structure. South Pacific Studies, 28, 9-22 (2007).

Islam, M.S., M.A.S. Miah, M.K. Alam, M.R. Begum and M.S. Arefin: Growth, yield and juice quality of some selected sugarcane clones under waterlogging stress condition. World J. Agri. Sci. 7, 504-509 (2011).

Jain, R., A. Singh, S. Singh, C.P. Singh, R.K. Singh, S.P. Singh, V.K. Srivastava, A. Chandra, A.D. Pathak and S. Solomon: Variation in juice quality traits of sugarcane genotypes under waterlogged condition in subtropical India. Climate Change Environ. Sustain., 5, 50-58 (2017b).

Jain, R., A. Singh, S. Singh, S.P. Singh, V.K. Srivastava, A. Chandra, A.D. Pathak and S. Solomon: Physio-biochemical characterization of sugarcane genotypes for waterlogging tolerance. World J. Agri. Sci., 13, 90-97 (2017a).

Kaur, G., H.P. Singh, D.R. Batish and R.K. Kohli: A time course assessment of changes in reactive oxygen species generation and antioxidant defense in hydroponically grown wheat in response to lead ions $\left(\mathrm{Pb}^{2+}\right)$. Protoplasma, 249, 1091-1100 (2012).

Ooume, K., Y. Inoue, K. Soga, K. Wakabayashi, S. Fujii, R. Yamamoto and T. Hoson: Cellular basis of growth suppression by submergence in azuki bean epicotyls. Ann. Bot., 103, 325-332 (2009).

Ponnamperuma, F.N.: The chemistry of submerged soil. Advances in Agron., 24, 29-95 (1972).

Rahman, A.B.M.M., F.A. Martein and M.E. Terry: Physiological response of sugarcane to flooding stress. Proc. Int. Soc. Sugarcane Tech., 20,668-67 (1989)

Vitorino, P.G., J.D. Alves, P.C. Magalhăes, M.M. Magalhăes, L.C.O. Lima and L.E.M. Oliveira: Flooding tolerance and cell wall alterations in maize mesocotyl during hypoxia. Pesq. Agropec. Bras., 36, 1027-1035 (2001).

Webster, P.W.D. and E.W. Eavis: Effect of flooding on sugarcane growth duration of flooding. Proc. Int. Soc. Sugarcane Tech., 14, 708-714 (1972).

Yamauchi, T., A. Tanaka, H. Mori, I. Takamure, K. Kato and M. Nakazono: Ethylene-dependent aerenchyma formation in adventitious roots is regulated differentially in rice and maize. Plant Cell Environ., 39, 2145-2157 (2016)

Yamauchi, T., T.D. Colmer, O. Pedersen and M. Nakazono: Regulation of root traits for internal aeration and tolerance to soil waterloggingflooding stress. Plant Physiol., 176, 1118-1130 (2018). 